\title{
Mineral diagnostics: SEM-EDS Monte Carlo strategy for optimised measurements of ultrathin fragments in cultural heritage studies
}

\author{
Daniele Moroํ, Gianfranco Ulian¹, Giovanni Valdrè ${ }^{1}$ \\ ${ }^{1}$ Centro di Ricerca Interdisciplinare di Biomineralogia, Cristallografia e Biomateriali, Dipartimento di Scienze Biologiche, Geologiche e \\ Ambientali, “Alma Mater Studiorum" Università di Bologna, Piazza di Porta San Donato 1, 40126 Bologna, Italy
}

\begin{abstract}
The availability of minute quantities of sampling material is often an issue in the context of cultural heritage and archaeology due, for instance, to the value of the sample, its uniqueness or the small amount of residual material which testify the original form of the art to be restored. In this context, electron-excited energy-dispersive X-ray spectrometry (EDS) performed in a scanning electron microscope (SEM) has proven to be a primary methodology for analysing minute quantities of material thanks to its morphological and microanalytical capability. However, when dealing with micro- and sub-micrometre specimens, as can be the case in ultrathin glass and metal fragments, several effects resulting from the physics and operational settings of the measurement must be considered to avoid quantification errors. In this paper, a detailed study of the effects of micro- and nanometric-sized glass and gold-alloy fragments on SEMEDS microanalysis is presented. Monte Carlo simulations of different kinds of elongated glass fragment, with a square section and a thickness of 0.1 to $10 \mu \mathrm{m}$, and of some gold alloys demonstrated a strong influence in terms of the fragment size and operational conditions (beam energy, detector position, etc.). This work can be used to devise an appropriate and optimised measurement strategy.
\end{abstract}

Section: RESEARCH PAPER

Keywords: Monte Carlo method; SEM-EDS microanalysis; glass fragments; metal fragments

Citation: Daniele Moro, Gianfranco Ulian, Giovanni Valdrè, Mineral diagnostics: SEM-EDS Monte Carlo strategy for optimised measurements of ultrathin fragments in cultural heritage studies, Acta IMEKO, vol. 10, no. 1, article 26, March 2021, identifier: IMEKO-ACTA-10 (2021)-01-26

Editor: Ioan Tudosa, University of Sannio, Italy

Received April 28, 2020; In final form November 11, 2020; Published March 2021

Copyright: This is an open-access article distributed under the terms of the Creative Commons Attribution 3.0 License, which permits unrestricted use, distribution, and reproduction in any medium, provided the original author and source are credited.

Corresponding authors: Giovanni Valdrè, e-mail: giovanni.valdre@unibo.it

\section{INTRODUCTION}

Morphological, chemical, structural and other types of analyses, which are of paramount importance in the conservation and restoration of cultural heritage artefacts, are often faced with the impossibility of sampling a suitable quantity of material to apply conventional, well-established procedures of analysis. In these cases, where a very small amount of material is available, micro- and nano-scale methodologies are of fundamental importance to provide precise and accurate results for the characterisation, and hence, conservation and restoration, of the artefact. Among the different advanced experimental and theoretical methodologies with micro- and sub-micrometric scale capability for the characterisation of natural or synthetic materials [1]-[8], scanning electron microscopy (SEM), coupled with energy dispersive X-ray spectrometry (EDS) with $\mathrm{Si}(\mathrm{Li})$ detectors or silicon drift detectors (SDD), is a very powerful and widely used microanalytical technique to study both the local morphology and chemical composition of materials found in the cultural heritage field [9]-[13], even when their dimensions are on the micro- and nanometre scale. This is typical of ceramics, lithotypes and glass fragments as well as ultrathin metal and alloy layers and fragments.

However, in the latter, and particularly whenever a quantitative assessment is desired, the SEM-EDS parameter setup and the EDS detector-to-sample configurations and arrangements have to be optimised because, if not set appropriately, the electron and X-ray scattering in the ultrathin materials, and even in those adjacent, could generate systematic errors. These problems are related to the elastic/inelastic scattering of energetic electrons in the finite size (mass) of the fragment, which is also affected by the mean atomic number. As a consequence, the EDS spectrum X-ray intensity is mainly influenced by the ratio between the fragment size and the extension of the electron path in the material. In order to avoid, 
or at least control, these phenomena when a quantitative analysis of ultrathin fragments is desired, the SEM-EDS operational conditions (e.g. beam energy, etc.) have to be optimised to design specific analytical strategies, which consider both the chemical composition, the size of the specimen and the detector configuration. In particular, a systematic study of the optimal instrumental settings is required to achieve precise, accurate and consistent results.

In this study, a Monte Carlo simulation [14] was proposed as an effective methodology to assess the appropriate strategy for an accurate quantitative SEM-EDS microanalysis of ultrathin samples. The Monte Carlo method was applied to simulate the transport of energetic electrons and X-ray generation and detection in two different types of ultrathin sample. To show the potential of the method, we chose two typical case studies from cultural heritage and archaeology. The first case study presents an investigation of ultrathin and elongated glass fragments with a square section. In the second case, ultrathin metal layers, such as those used in the glass tesserae of mosaics, were simulated and studied. All the simulations were carried out modelling realistic experimental conditions, investigating the effects related to the composition and thickness of the glass and metal fragments, the physics of electron beam-sample interaction (e.g. energy of the electron beam, elastic/inelastic scattering of electrons, threshold levels for element ionisation) and the SEM-EDS chamber setups (e.g. detector azimuthal and take-off angles, position of the electron beam on the sample).

The results of this study are of interest to researchers in the field of cultural heritage and archaeology because of the potential for using SEM-EDS micro-nanoanalysis to obtain detailed, precise and accurate quantitative data from ultrathin fragments and objects. The presented Monte Carlo-based approach is a general, consistent and accurate strategy applicable whenever the ultrathin size of the investigated specimen is comparable to or less than the volume of the electron scattering, for example, of micron size. In the field of cultural heritage and archaeology, this is often the case, for instance, in ultrathin pigment layers, alteration and contamination layers, oxidised metal surfaces, superficial protective treatments and micro- and nanometric dishomogeneity.

In section 2, the physics of the Monte Carlo model is introduced together with the specific SEM-EDS settings used in this study. In section 3, the results of the Monte Carlo investigation of two relevant case studies (ultrathin glass fragments and metal layers) are presented and discussed. Finally, section 4 reports the main conclusions of this study.

\section{MONTE CARLO MODEL}

The SEM Monte Carlo method is an efficient solution for dealing with a detailed study of the scattering of electrons and the generation, absorption and fluorescence of X-rays in different kinds of material. This method was employed here to model the generation and transport of electrons and the generation and transport of continuum [15]-[18] and characteristic X-ray photons, also considering secondary fluorescence, in ultrathin structures and to model a realistic EDS $\mathrm{X}$-ray detector, with the aim of achieving an optimised and accurate quantitative SEM-EDS X-ray microanalysis. The trajectories of electrons were modelled taking into account elastic scattering and continuous energy loss (continuous slowing down approximation) [19]. Czyzewski et al.'s Mott cross section [20], Jablonski et al.'s Mott scattering cross section [21] and a basic screened Rutherford model [22] were considered for the elastic scattering. Energy loss was modelled through an empirical modification of the Bethe equation for energy loss (Joy-Luo expression [23]), and the Bote and Salvat expression [24] was employed for the ionisation cross section. The mass absorption coefficients are those of Chantler et al. [25], whereas the fluorescence yields are tabulated experimental values [26].

The physics of X-ray secondary fluorescence generation is modelled by propagating the emitted primary, Bremsstrahlung and characteristic X-ray photons from the generation point in a random direction (from a uniform distribution) for a distance computed by the mean free path for photoionisation, until absorption by photoionisation, or until they exit the material [27]. In the case of a photoionisation event, relaxation follows with the related probabilities of characteristic X-ray emissions.

The electron beam was modelled with a Gaussian profile and focussed onto three-dimensional models of the glass and metal fragments. The EDS spectra were obtained simulating a realistic $\mathrm{Si}(\mathrm{Li})$ EDS detector, with a Moxtek AP 3.3 ultrathin polymer window, a resolution of $130 \mathrm{eV}$ (FWHM at Mn K $\alpha$ ), a sampleto-detector distance of $45 \mathrm{~mm}$ and an elevation angle of $40^{\circ}$, which are typical measurements in SEM-EDS microanalysis. After the spectra generation, the background was subtracted, the intensities of the characteristic peaks were integrated and the resulting values analysed against fragment size, beam energy, position of the electron beam with respect to the fragment edges and orientation of the long axis of the fragment with respect to the detector position (azimuthal angle). Specimen coating by conductive layers were not considered.

\section{RESULTS AND DISCUSSION}

In general, for the microanalytical characterisation of the composition of very thin material, the requirements of the quantitative SEM-EDS approach need special care since several phenomena can influence the analytical results. This is particularly evident with ultrathin materials whose dimensions are close to or below that of the electron penetration volume. The interaction volume of energetic electrons and the X-ray generation volume in conventional X-ray microanalysis (i.e. 15$30 \mathrm{keV}$ ) extend for several $\mu \mathrm{m}^{3}$ in many materials. For ultrathin materials, it is expected that the penetration of primary electrons extends further than the fragment size, with a variable percentage of electrons exiting the fragment before exciting $\mathrm{X}$-rays (finite size effect). In turn, they may excite the adjacent materials or even the substrate, generating X-rays not related to the intended material. Furthermore, the typical standard reference samples used in conventional quantitative microanalysis are bulk materials (i.e. of infinite size with respect to the scattering volume of electrons); therefore, more X-rays are generated in a standard reference sample than an ultrathin fragment. Accordingly, the ratio of the X-ray intensity emitted by the unknown fragment to that of a massive sample (k-ratio) is subject to a decrement. These phenomena must be carefully taken in account to improve the precision and accuracy of the analysis.

\subsection{Case study 1: glass fragments}

To investigate the various effects of different SEM-EDS measurement conditions on the electron-excited X-ray microanalysis of ultrathin glass samples, three different types of glass of varying thickness and composition were considered: (A) silica-iron-magnesium glass, (B) sodium-bearing glass and (C) calcium-bearing glass (see Table 1 for the specific compositions, reported in oxides). Three-dimensional glass fragments were 

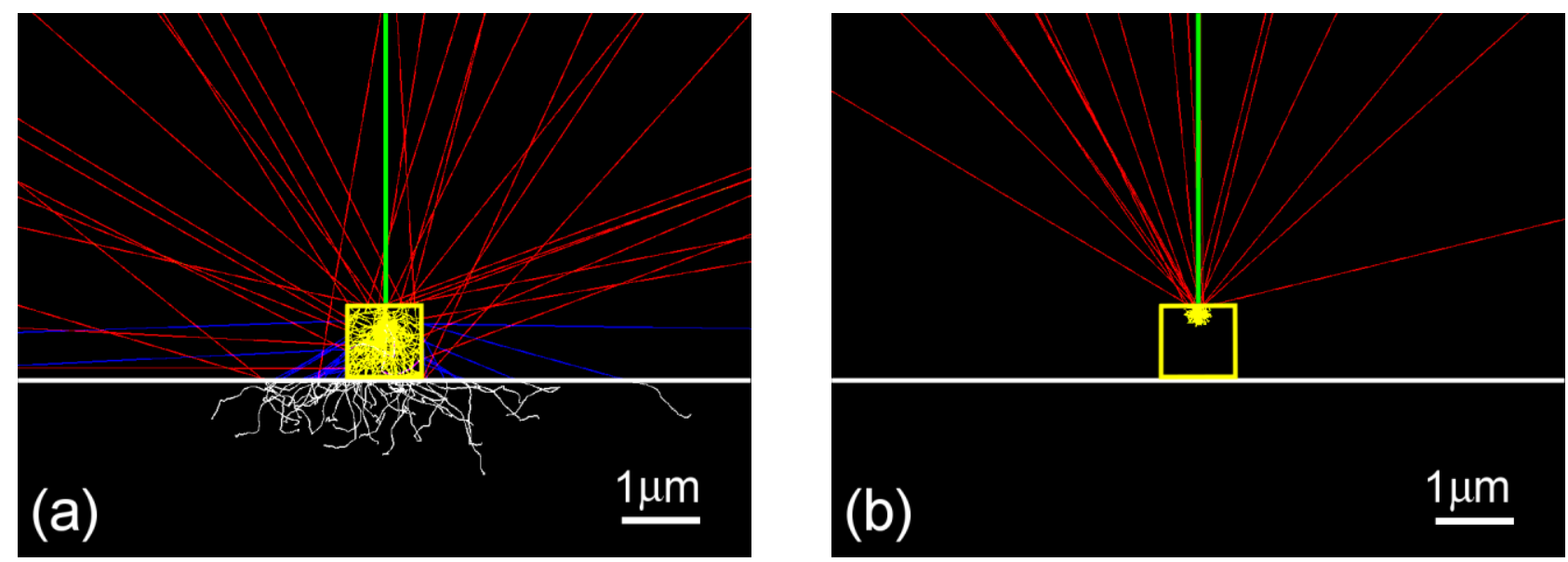

Figure 1. Simulated electron trajectories for a 1- $\mu$ m-thick glass fragment of composition $\mathrm{SiO}_{2} 53 \%, \mathrm{Fe}_{2} \mathrm{O}_{3} 35 \%, \mathrm{Na}_{2} \mathrm{O} 8 \%, \mathrm{MgO} 4 \%$ (type $\mathrm{B}$ in Table 1 ) and beam energies of $15 \mathrm{keV}(\mathrm{a})$ and $5 \mathrm{keV}(\mathrm{b})$, under the experimental conditions detailed in section 2. Electron trajectory colour: green - electron beam, yellow - inside the fragment, white - inside the substrate, blue - escaping from the fragment sides towards the substrate, red - scattering outside both the fragment and substrate.

modelled with a square section in the $\mathrm{x}-\mathrm{z}$ plane and an elongated shape in the third dimension, deposited above a massive substrate of carbon. For each model, the thickness and lateral size of the fragment were varied between 0.1 and $10 \mu \mathrm{m}$ to investigate the effects of size reduction, whereas electron beam energies of 5, 15 and $25 \mathrm{keV}$ were employed.

It was found that several effects should be carefully considered when the excitation volume approaches the size of the fragment under analysis, and the experimental setting must be accurately defined accordingly.

Table 1. Oxide composition (weight \%) of the glass fragments.

\begin{tabular}{cccccc}
\hline Type & SiO2 & Fe2O3 & Na2O & CaO & MgO \\
\hline A & 53 & 40 & - & - & 7 \\
\hline B & 53 & 35 & 8 & - & 4 \\
\hline C & 62 & 2 & - & 14 & 22 \\
\hline
\end{tabular}

Figure $1 \mathrm{a}$ and $\mathrm{b}$ show, as an example, a two-dimensional view of the electron trajectories in the case of a $15 \mathrm{keV}$ (a) and $5 \mathrm{keV}$ (b) electron beam (vertical green line), respectively, focussed on the top of a sodium-bearing glass fragment (yellow square line), type B of Table 1 . The beam is centred with respect to the fragment edges. The fragment has a square section, a thickness of $1 \mu \mathrm{m}$ and is deposited onto a carbon substrate (horizontal white line). In this case, working at $15 \mathrm{keV}$ (Figure 1a) does not prevent the electrons from escaping from the fragment towards the surrounding material. Primary electrons scatter inside the whole fragment volume (yellow trajectories), even scattering into the carbon substrate (white trajectories) underneath and from the sides of the fragment towards the substrate (blue trajectories) or escaping from each different type of material (red ones). Primary electrons penetrate the substrate for more than $1 \mu \mathrm{m}$, laterally spreading for several micrometres. Reducing the beam energy to $5 \mathrm{keV}$ (Figure 1b) deeply affects the electron scattering volume, which reduces to about $4 \times 10^{-2} \mu \mathrm{m}^{3}$, completely confined within the glass material and without any contribution from the substrate. Furthermore, it is worth noting that, compared to the $5 \mathrm{keV}$ electron beam, when working at $15 \mathrm{keV}$, the electrons also laterally scatter from the fragment sides (blue and red trajectories). In the case of an embedded fragment, at $15 \mathrm{keV}$, these last electrons excite $\mathrm{X}$-ray generation in the material adjacent to the glass fragment.
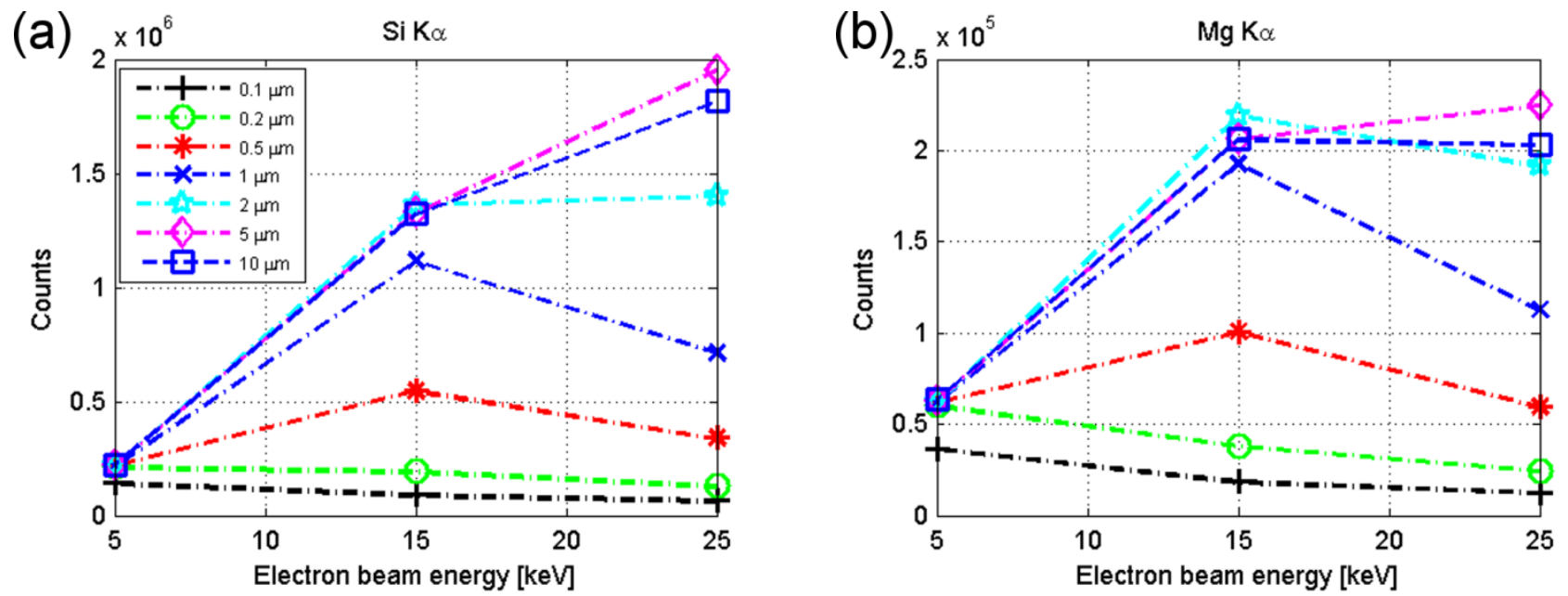

Figure 2. Integrated X-ray intensity of $\mathrm{Si} \alpha \alpha(\mathrm{a})$ and $\mathrm{Mg} \mathrm{K \alpha}(\mathrm{b})$ emission lines versus electron beam energy, simulated for type-A glass fragments with a square section and thicknesses between 0.1 and $10 \mu \mathrm{m}$. Legend in (a). 
(a)

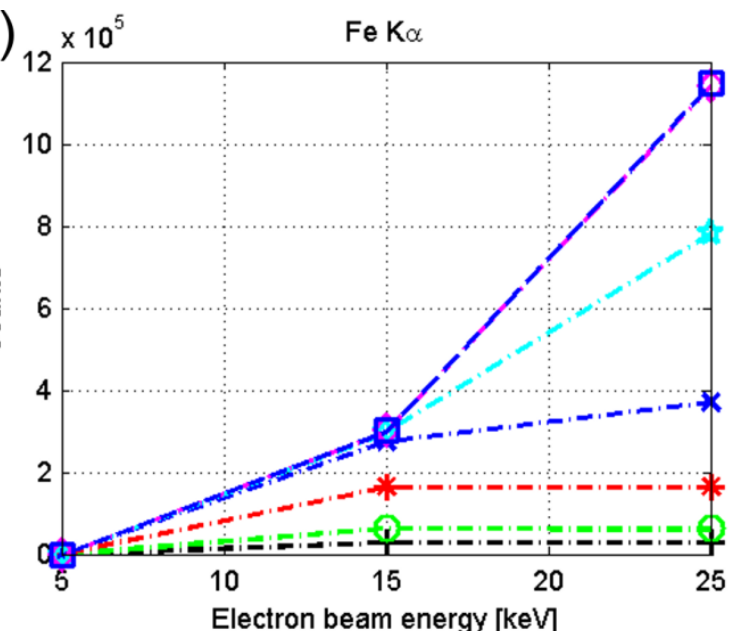

$(\mathrm{c})_{3.5}$

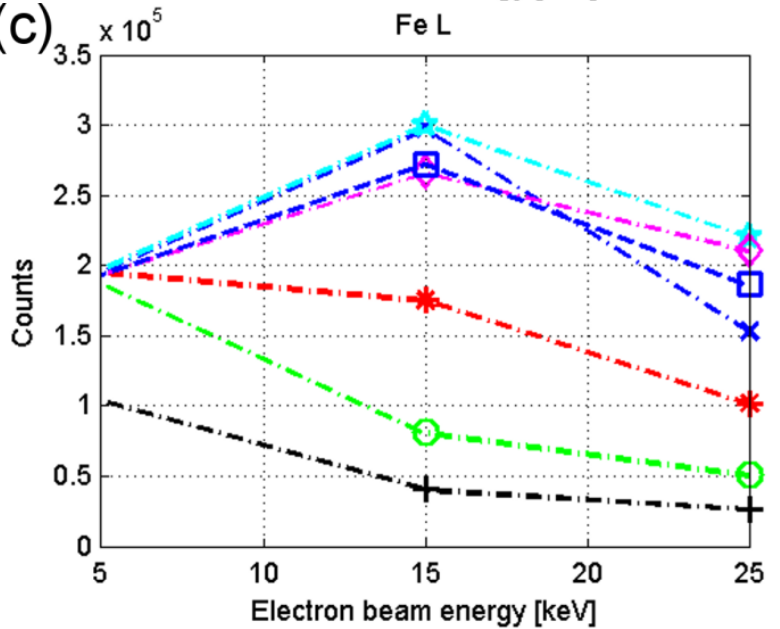

(e)

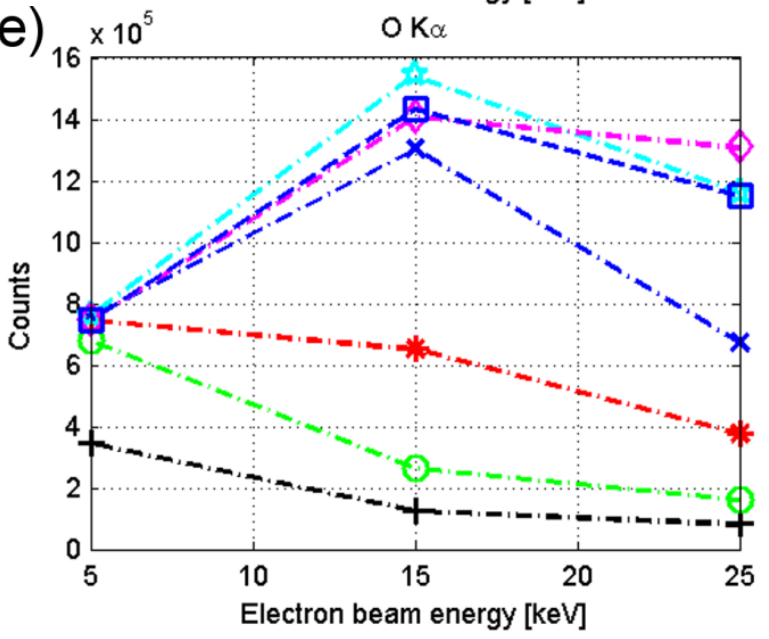

(b)

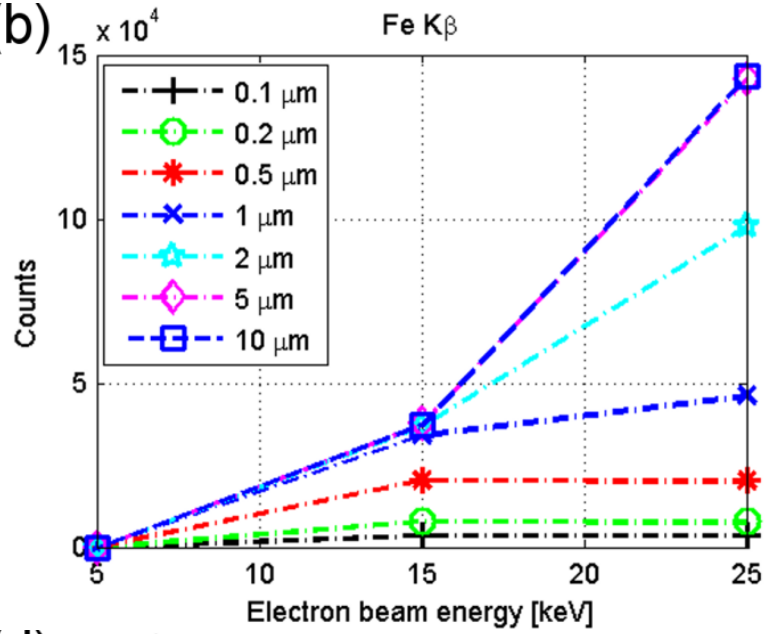

(d)

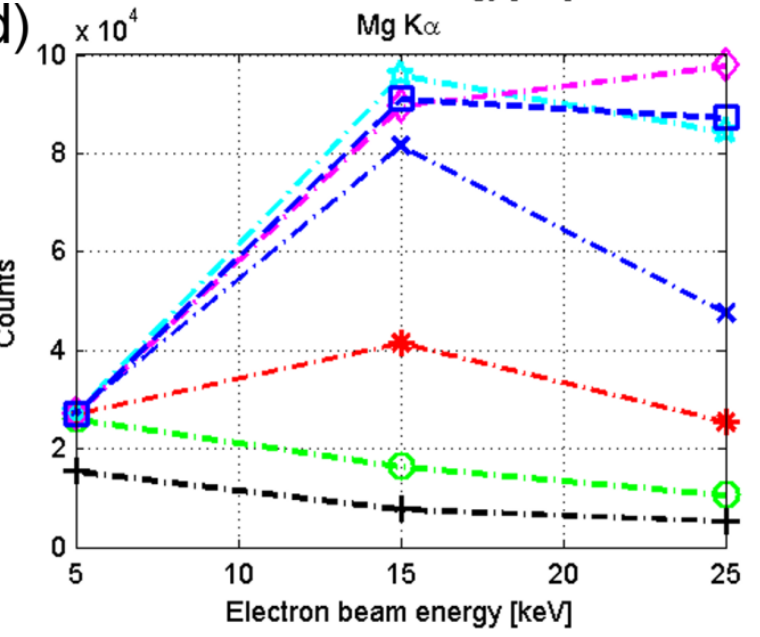

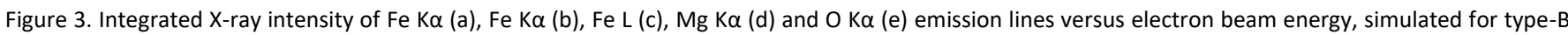
glass fragments with a square section and thicknesses between 0.1 and $10 \mu \mathrm{m}$. Legend in (b).

The EDS spectra, obtained by the specific modelled $\mathrm{Si}(\mathrm{Li})$ detector and SEM chamber setup, were background subtracted, and the intensity of the relevant X-ray peaks was integrated. These values were also compared with those obtained for a bulk glass reference standard. As an example, the integrated intensity (counts) of some $\mathrm{X}$-ray emission lines as a function of the energy of the electron beam $(5,15$ and $25 \mathrm{keV})$, for thicknesses of 0.1 , $0.2,0.5,1.0,2.0,5.0$ and $10.0 \mu \mathrm{m}$, is shown in Figure 2, Figure 3 and Figure 4, in relation to a type-A, $-\mathrm{B}$ and $-\mathrm{C}$ glass fragment, respectively.
It is worth noting that the integrated intensity trend of the Si $\mathrm{K} \alpha$ emission line $(1.740 \mathrm{keV})$ for the type-A glass, as opposed to the beam energy (Figure 2a), is highly variable with regard to fragment thickness, and it has a general non-linear trend. The Xray emission of a $10-\mu \mathrm{m}$-thick fragment (blue dashed line and square marker) is comparable with that of the bulk material for each simulated energy of the electron beam. With the decrease in glass-fragment thickness and lateral size, a strong reduction in the integrated intensity was observed, with a different thickness threshold and non-linear trend for each electron-beam energy value. At $25 \mathrm{keV}$, a reduction in fragment thickness to $5 \mu \mathrm{m}$ is 
(a)

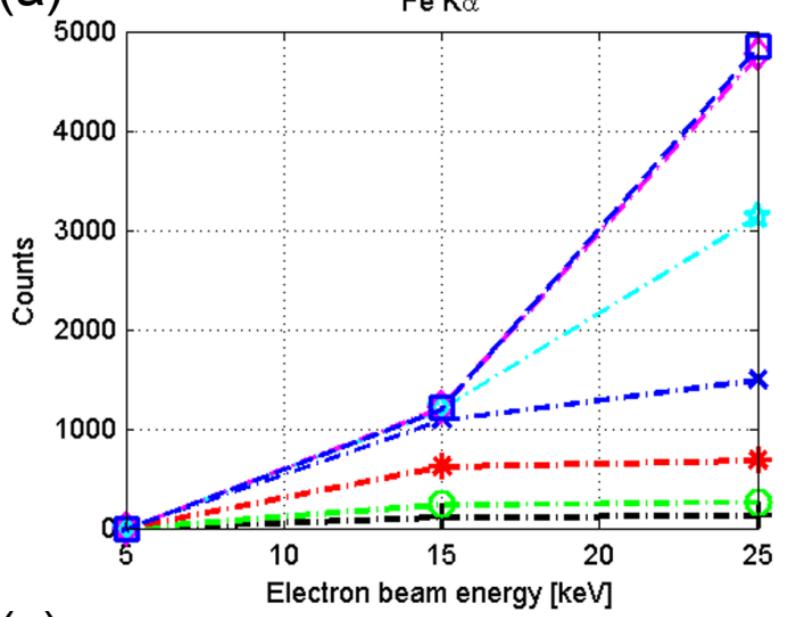

(c)

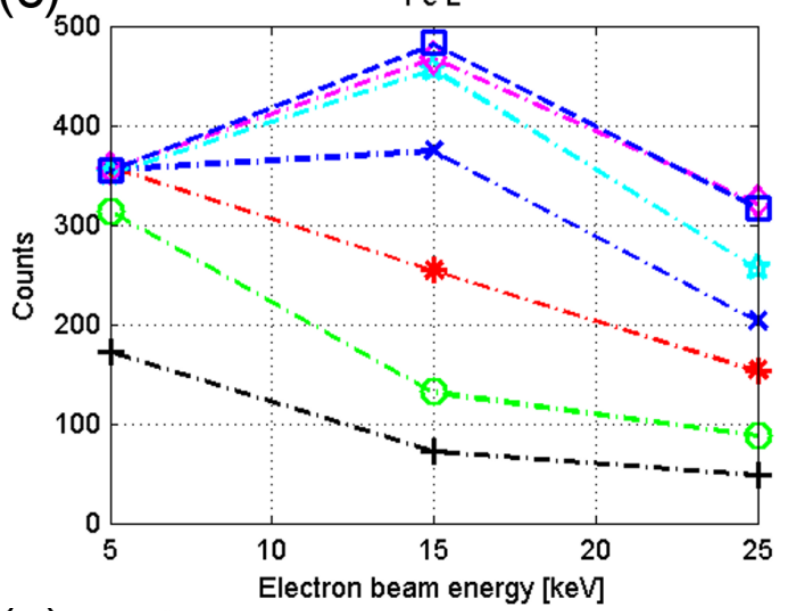

(e)

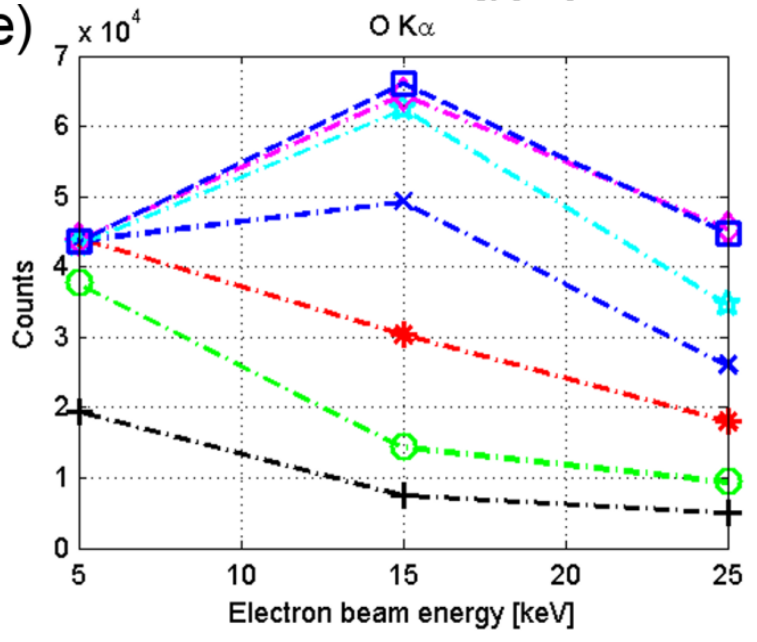

(b)

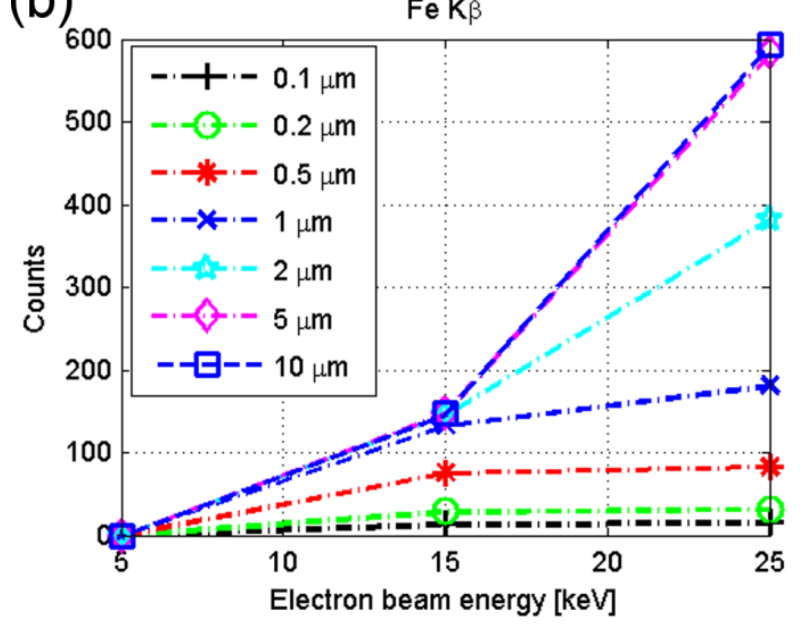

(d)

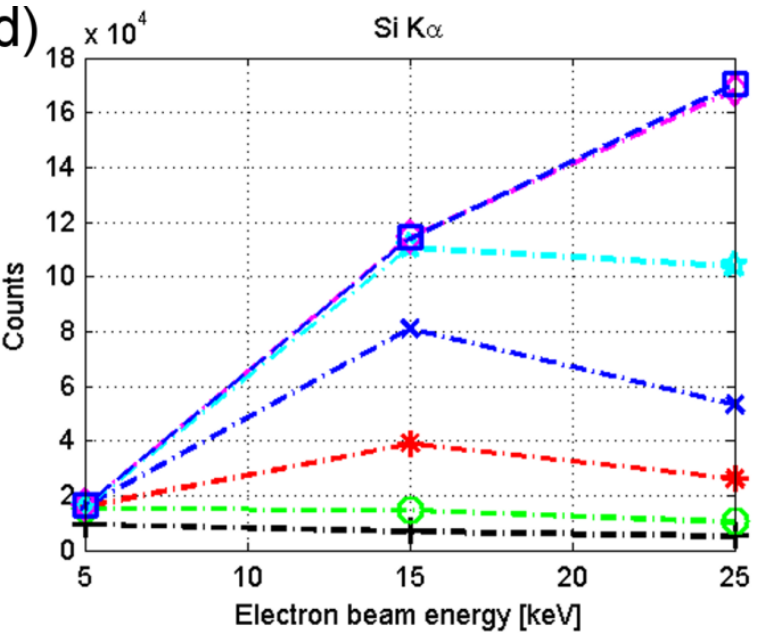

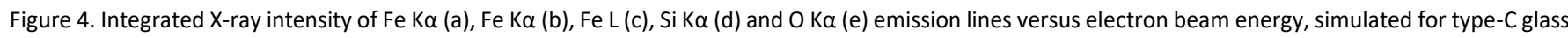
fragments with a square section and thicknesses between 0.1 and $10 \mu \mathrm{m}$. Legend in (b).

enough to induce a deviation in integrated intensity from that of the bulk standard. For this thickness value, the reduced absorption effect prevails over that of reduced mass (size), and an increase in X-ray counts measured by the detector is observed. It should be noted that 'soft' $\mathrm{X}$-rays, which are subject to higher absorption, suffer a greater reduced X-ray absorption effect [28]. For thicknesses below $5 \mu \mathrm{m}$, the X-ray counts are strongly reduced with respect to that of the bulk material. At $15 \mathrm{keV}$, the detected X-ray counts start reducing below $2 \mu \mathrm{m}$, whereas the same effect occurs below $0.5 \mu \mathrm{m}$ at $5 \mathrm{keV}$.
Figure $2 \mathrm{~b}$ shows the results obtained for the integrated intensity of the $\mathrm{Mg} \mathrm{K} \alpha$ emission line $(1.254 \mathrm{keV})$ for the type- $\mathrm{A}$ glass fragment. Similar considerations made for $\mathrm{Si} \mathrm{K} \alpha$ can be extended to the general trend of this atomic species, although with different variations specific to $\mathrm{Mg} \mathrm{K} \alpha$. In particular, a higher reduced absorption effect is observed for the less energetic $\mathrm{Mg}$ $\mathrm{K} \alpha$ line compared with $\mathrm{Si} \mathrm{K} \alpha$ (see also the counts at $15 \mathrm{keV}$ for the $2-\mu \mathrm{m}$-thick fragment, cyan dash-dot line and star marker).

The integrated intensity for Fe K $\alpha(6.400 \mathrm{keV}), \mathrm{Fe} \mathrm{K} \beta$ (7.059 $\mathrm{keV}), \mathrm{Fe} \mathrm{L}(\mathrm{L} \alpha+\mathrm{L} \beta+\mathrm{L} \gamma ; 0.712 \mathrm{keV}), \mathrm{Mg} \mathrm{K} \alpha(1.254 \mathrm{keV})$ and 
$\mathrm{O} \mathrm{K} \alpha(0.523 \mathrm{keV})$ in the type- $\mathrm{B}$ glass fragment is presented in Figure 3. Fe $\mathrm{K} \alpha$ (Figure $3 \mathrm{a}$ ) and $\mathrm{K} \beta$ (Figure $3 \mathrm{~b}$ ) have a comparable non-linear trend, variable with the fragment thickness. The X-ray emission of 5- and 10- $\mu \mathrm{m}$-thick fragments (magenta dash-dot line and diamond marker, blue dashed line and square marker, respectively) are superimposed and comparable with that of a bulk material for each simulated energy of the electron beam. However, a strong non-linear reduction in the integrated intensity was observed as a function of the fragment size below $5 \mu \mathrm{m}$ at $25 \mathrm{keV}$ and $2 \mu \mathrm{m}$ at $15 \mathrm{keV}$, whereas at $5 \mathrm{keV}$, these emission lines could not be excited. The lower energy emission lines of $\mathrm{Fe} \mathrm{L}, \mathrm{Mg} \mathrm{K} \alpha$ and $\mathrm{O} \mathrm{K} \alpha$ (Figure $3 \mathrm{c}$, d and e), particularly Fe L and $\mathrm{O} \mathrm{K} \alpha$, presented a marked increase in X-ray intensity before the reduction threshold due to a higher contribution of the reduced absorption effect with respect to that of reduced mass. A specific trend was observed for each X-ray line, with intensity reduction thresholds at $5 \mu \mathrm{m}(25 \mathrm{keV}), 2 \mu \mathrm{m}$ $(15 \mathrm{keV})$ and $0.5 \mu \mathrm{m}(5 \mathrm{keV})$. Only the Fe L line revealed different thresholds: $2 \mu \mathrm{m}(25 \mathrm{keV}), 1 \mu \mathrm{m}(15 \mathrm{keV})$ and $0.5 \mu \mathrm{m}$ $(5 \mathrm{keV})$.

Figure 4 shows, for the type- $\mathrm{C}$ glass fragment, the integrated intensity of Fe $\mathrm{K} \alpha(6.400 \mathrm{keV}), \mathrm{Fe} \mathrm{K} \beta(7.059 \mathrm{keV}), \mathrm{Fe} \mathrm{L}(\mathrm{L} \alpha+$ $\mathrm{L} \beta+\mathrm{L} \gamma ; 0.712 \mathrm{keV}), \mathrm{Si} \mathrm{K} \alpha(1.740 \mathrm{keV})$ and $\mathrm{O} \mathrm{K} \alpha(0.523 \mathrm{keV})$, providing further details on the effects of different chemical compositions on the trend of the integrated X-ray intensities. The Fe K $\alpha$ (Figure 4a) and Fe K $\beta$ (Figure 4b) emission lines have trends close to those of the type-B glass fragment (Figure $3 a, b$ ). The Si K $\alpha$ X-ray emission (Figure 4d) for the 5- and 10- $\mu \mathrm{m}$-thick fragments (magenta dash-dot line and diamond marker, blue dashed line and square marker, respectively) shows negligible deviations from that of a bulk material for each simulated energy of the electron beam, and no significant predominance of the reduced X-ray absorption effect was observed. In addition, for the less energetic X-ray lines, Fe L (Figure 4c) and O K $\alpha$ (Figure $4 \mathrm{e})$, a specific trend was observed with marked differences from that of the type-B glass (Figure 3c, e), with no significant predominance of the reduced X-ray absorption effect.

\subsection{Case study 2: ultrathin metal layers}

An ultrathin gold alloy ( $\mathrm{Au}, \mathrm{Ag}$ and $\mathrm{Cu}$ ) was selected and placed adjacent to extended natron glass supports (with a mass density of $2.5 \mathrm{~g} \mathrm{~cm}^{-3}$ ) to simulate a composite reproducing the structure of a mosaic tesserae [29]. A natron-type glass is a sodalime-silica glass found in ancient mosaic tesserae and characterised by low magnesium, potassium and phosphorous content [9], [10]. Two gold alloys were simulated varying the silver and copper weight $\%$, as shown in Table 2 .

Table 2. Composition (weight \%) and mass density of the gold alloys of the sub- $\mu$ m-thick layers.

\begin{tabular}{cccc}
\hline $\mathrm{Au}$ & $\mathrm{Ag}$ & $\mathrm{Cu}$ & Mass density in $\mathbf{g} / \mathrm{cm}^{3}$ \\
\hline 97.0 & 2.7 & 0.3 & 19.1 \\
\hline 93.0 & 6.4 & 0.6 & 18.5 \\
\hline
\end{tabular}

Two thickness values of the gold layer were simulated, corresponding to realistic thick $(1 \mu \mathrm{m})$ and ultrathin $(200 \mathrm{~nm})$ gold layers found in ancient mosaics, as explained by Conventi et al. and Neri et al. [9], [10].

Furthermore, to investigate the effects of the metal-layer thickness on the chemical quantification, the same simulation approach was applied to bulk standards of the alloys with 'infinite' sizes for electron scattering effects. Reference calibration curves were obtained from the integrated intensities and compared with those of the elements of the metal layers.
Top view

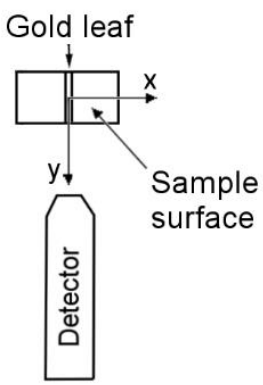

Top view

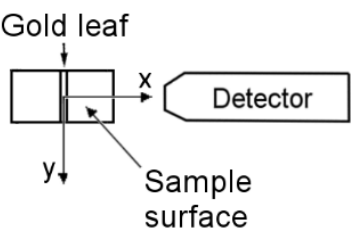

(a)
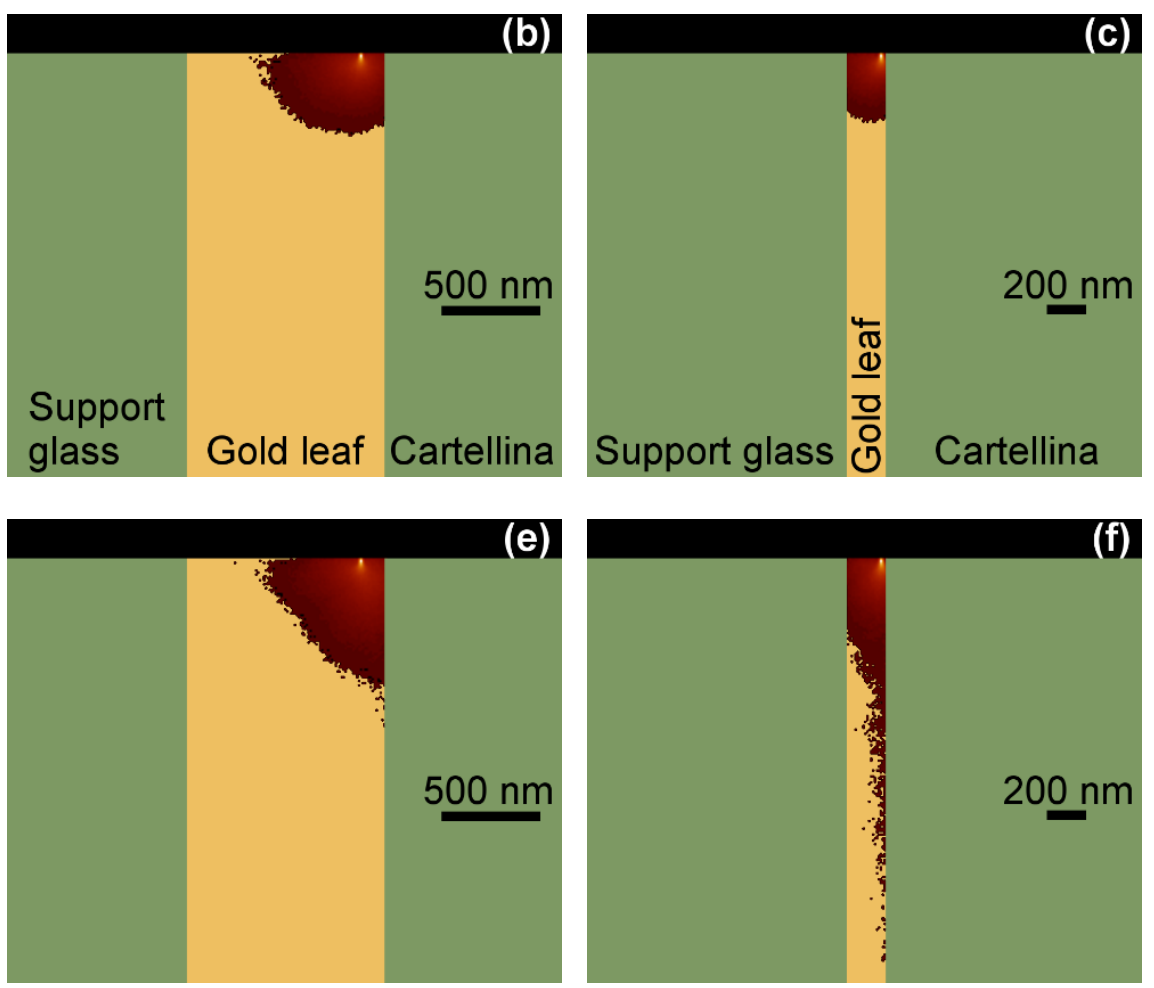

Figure 5. Images of the distribution of the detected X-rays (side view) for Ag L $\alpha_{1}$ in gold leaf $1 \mu \mathrm{m}(\mathrm{b}, \mathrm{e})$ and $200 \mathrm{~nm}$ (c, f) thick, with the detector oriented in the same direction as the leaf extension (b, c), as shown in the schematic diagram (a), or at $90^{\circ}$ (e, f), as shown in the schematic diagram (d), for a non-centred $25 \mathrm{keV}$ electron beam. The images depict a 3D distribution projected onto a 2D plane. 
The EDS microanalysis of the gold alloy could include a not negligible unreal contribution from X-ray fluorescence, produced when a Bremsstrahlung or characteristic primary X-ray photoionises core/shell electrons of elements present in the surrounding materials but not in the gold alloy. When the gold layer is ultrathin and elements, even in trace, are present in the adjacent material (in our simulation, the glass of the mosaic tesserae), X-ray fluorescence from the surrounding material should be considered for a correct quantification of the metal layer composition, otherwise incorrect results are obtained, with elements present in the glass being assigned to the gold alloy. In fact, it should be considered that secondary fluorescence can be generated in a material outside the electron scattering volume because the mean free path of energetic X-rays overrides electron spreading in most materials. In the present simulations, the secondary fluorescence contribution was considered.

The results provided evidence that for a SEM-EDS microanalysis of a $1-\mu \mathrm{m}$-thick gold layer performed using operational settings such as a $25 \mathrm{keV}$ beam positioned in the middle of the gold layer, when the sample is oriented so that the layer's long axis is aligned with the detector, the resulting $\mathrm{X}$-ray intensity value is very close to the reference calibration curves. Conversely, the same operational conditions, when applied to the microanalysis of a 200 -nm-thick gold layer, would have a strong negative effect on the accuracy of the quantitative measurement, with a calculated deviation (error) from the real composition of about 33\% for silver and 53\% for copper [29].

As a different case study, the effect of a non-ideally centred electron beam with respect to an ultrathin layer, a tilted layer or a layer that was not homogeneously prepared (Figure 5) was also evaluated. The EDS detector was oriented in axis with (Figure $5 \mathrm{a}$ ) or at $90^{\circ}$ (Figure 5d) to the gold layer, and the layer thickness varied between $1 \mu \mathrm{m}$ and $200 \mathrm{~nm}$. For the sake of this example, Figure 5 demonstrates the distribution of the detected $\mathrm{X}$-rays for $\mathrm{Ag} \mathrm{L} \alpha_{1}$ in a gold leaf $1-\mu \mathrm{m}$ thick (Figure 5b, e) and $200 \mathrm{~nm}$ thick (Figure 5c, f), with the detector oriented in the same direction as the leaf extension (Figure 5b, c) or at $90^{\circ}$ (Figure 5e, f), for a noncentred $25 \mathrm{keV}$ electron beam. In Figure $5 \mathrm{~b}$, the considered operational settings cause a reduction in X-ray generation volume inside the layer with a consequent non-linear decrease in detected X-rays from the gold alloy and important contributions from the elements in the adjacent glass layer (cartellina). The reduction in gold-layer thickness to $200 \mathrm{~nm}$ further increases these effects, decreasing the detected $\mathrm{Ag} \mathrm{X}$-rays with respect to a bulk reference sample and adding to the measured spectrum further spurious contributions from the glass layer present on the left (support glass). It should also be noted that the orientation of the gold leaf with respect to the detector azimuthal angle affects the distribution of the detected X-ray emissions. In contrast, as shown in Figure 5e and Figure 5f, a configuration with the detector at $90^{\circ}$, i.e. positioned in the direction of the cartellina glass, extends the distribution of detected X-rays inside the gold alloy in a non-symmetrical manner. Indeed, Figure $5 \mathrm{e}$ and Figure $5 \mathrm{f}$ show an increase along the $\mathrm{z}$-axis (depth) of the $\mathrm{X}$ ray volume revealed by the detector, in both the $1-\mu \mathrm{m}$-thick and 200-nm-thick layers. This effect is due to the different detector position with respect to the gold alloy/glass edges, which causes a variation in the $\mathrm{X}$-ray absorption path from the generation point to the detector. More X-rays will pass through the glass layer, a less dense material and with lighter elements than the gold alloy. It should be noted that the detected X-ray signal, even if the electron beam is focussed on the gold alloy, would present $\mathrm{X}$-ray lines from the glass composition. In this regard, it should be considered that the interaction volume of electrons, and the associated X-ray generation, is highly dependent on material composition and electron-beam energy. The penetration of energetic electrons is influenced by elastic and inelastic scattering events inside the specific material that can generate a lateral extension of electron trajectories from hundreds of nm to several $\mu \mathrm{m}$.

To optimise the quantitative SEM-EDS microanalysis of an ultrathin, 200-nm-thick gold layer, as in the case of a gold-leaf mosaic tesserae, the Monte Carlo simulation results suggest a decrease in beam energy to $7.5 \mathrm{keV}$. Under this condition, the $\mathrm{X}$ ray signal generation is confined within the ultrathin gold fragment, which therefore behaves as a massive material.

\section{CONCLUSIONS}

In the quantitative SEM-EDS microanalysis of ultrathin fragments and objects of interest in cultural heritage and archaeology, the volume of electron scattering could be comparable to the size of such fragments. The present study showed that, in these cases, the interplay between the experimental settings, operational parameters and ultrathin fragment sizes can produce multiple and complex effects that strongly impact the intensity of the detected X-rays and, hence, the exact quantification. Several potential error sources can affect the quantitative SEM-EDS X-ray microanalysis of ultrathin samples, such as glass fragments and metal layers, which may have negative consequences on indirect outcomes (e.g. artefact dating, historical records, geographical origin and geological setting). The simulation results demonstrated that quantification errors may be affected by sample size, chemical composition, the energy of the electron beam and several other experimental settings, with a specific trend for each analysed element. For this reason, for ultrathin fragments, Monte Carlo simulations should be adopted to identify potential error sources and devise the experimental settings necessary to improve and optimise the precision and accuracy of the quantitative microanalysis of this kind of material.

\section{REFERENCES}

[1] A. Calia, M. Lettieri, G. Quarta, Cultural heritage study: microdestructive techniques for detection of clay minerals on the surface of historic buildings, Appl. Clay Sci. 53 (2011) pp. 525-531. DOI: $10.1016 /$ j.clay.2010.10.021

[2] D. Moro, G. Ulian, G. Valdrè, 3D meso-nanostructures in cleaved and nanolithographed $\mathrm{Mg}$-Al-hydroxysilicate (clinochlore): topology, crystal-chemistry, and surface properties, Appl. Clay Sci. 169 (2019) pp. 74-80.

DOI: $10.1016 /$ j.clay.2018.12.020

[3] I. Angelini, Y. Asscher, M. Secco, M. Parisatto, G. Artioli, The pigments of the frigidarium in the Sarno Baths, Pompeii: identification, stratigraphy and weathering, J. Cult. Herit. 40 (2019) pp. 309-316. DOI: $10.1016 /$ j.culher.2019.04.021

[4] D. Moro, G. Ulian, G. Valdrè, Nanoscale cross-correlated AFM, Kelvin probe, elastic modulus and quantum mechanics investigation of clay mineral surfaces: the case of chlorite, Appl. Clay Sci. 131 (2016) pp. 175-181. DOI: $10.1016 /$ i.clay.2015.11.023

[5] G. Ulian, D. Moro, G. Valdrè, Probing the interaction of (001) carbonated hydroxylapatite surfaces with water: a density functional investigation, Micro \& Nano Lett. 13 (2018) pp. 4-8. DOI: $10.1049 / \mathrm{mnl} .2017 .0058$

[6] F. Dellisanti, A. Calafato, G.A. Pini, D. Moro, G. Ulian, G. Valdrè, Effects of dehydration and grinding on the mechanical shear 
behaviour of Ca-rich montmorillonite, Appl. Clay Sci. 152 (2018) pp. 239-248.

DOI: $10.1016 /$ i.clay.2017.11.019

[7] D. Moro, G. Valdrè, E. Mesto, F. Scordari, M. Lacalamita, G. Della Ventura, F. Bellatreccia, S. Scirè, E. Schingaro, Hydrocarbons in phlogopite from Kasenyi kamafugitic rocks (SW Uganda): cross-correlated AFM, confocal microscopy and Raman imaging, Sci. Rep. 7 (2017) art. 40663.

DOI: $10.1038 /$ srep40663

[8] G. Ulian, D. Moro, G. Valdrè, First principle investigation of the mechanical properties of natural layered nanocomposite: clinochlore as a model system for heterodesmic structures, Compos. Struct. 202 (2018) pp. 551-558. DOI: $10.1016 /$ i.compstruct.2018.02.089

[9] A. Conventi, E. Neri, M. Verità, SEM-EDS analysis of ancient gold leaf glass mosaic tesserae. A contribution to the dating of the materials, IOP Conf. Series: Mater. Sci. Eng. 32 (2012) art. 012007. DOI: $10.1088 / 1757-899 X / 32 / 1 / 012007$

[10] E. Neri, M. Verità, I. Biron, M.F. Guerra, Glass and gold: analyses of 4th-12th centuries Levantine mosaic tesserae. A contribution to technological and chronological knowledge, J. Archaeol. Sci. 70 (2016) pp. 158-171.

DOI: $10.1016 /$ i.jas.2016.05.003

[11] T. Z. Ferri, E. Pustijanac, I. Kovačić, J. Bilić, Micro-analytical evidence of copper-based pigment and fungal contamination of medieval mural paintings in Beram, Croatia, Microsc. Microanal. 25 (2019) pp. 1471-1481.

DOI: $10.1017 / \mathrm{S} 143192761901496 \mathrm{X}$

[12] G. Giacosa, D. Moro, G. Ulian, S. Zanna, G. Valdrè, Ceramic recipes: cross-correlated analytical strategy for the characterization of the Iron Age pottery from ancient Karkemish (Turkey), Measurement 128 (2018) pp. 180-188.

DOI: $10.1016 / \mathrm{i}$. measurement.2018.06.023

[13] N. Rovella, V. Comite, M. Ricca, The methodology of investigation on red- and black-figured pottery of unknown provenance, Int. J. Conserv. Sci. 7 (2016) pp. 955-964. Online [Accessed 17 March 2021] http://ijcs.ro/public/IJCS-16-SI2 15 Rovella.pdf

[14] D. Moro, G. Valdrè, Effect of shape and thickness of asbestos bundles and fibres on EDS microanalysis: a Monte Carlo simulation, IOP Conf. Series: Mater. Sci. Eng. 109 (2016) art. 012011.

DOI: $10.1088 / 1757-899 X / 109 / 1 / 012011$

[15] S. M. Seltzer, M. J. Berger, Bremsstrahlung spectra from electron interactions with screened atomic nuclei and orbital electrons, Nuclear Instruments and Methods in Physics Research Section B: Beam Interactions with Materials and Atoms 12 (1985) pp. 95-134. DOI: $10.1016 / 0168-583 X(85) 90707-4$

[16] S. M. Seltzer, M. J. Berger, Bremsstrahlung energy-spectra from electrons with kinetic-energy $1 \mathrm{keV}-10 \mathrm{Gev}$ incident on screened nuclei and orbital electrons of neutral atoms with $Z=1-100$, Atomic Data and Nuclear Data Tables 35 (1986) pp. 345-418. DOI: $10.1016 / 0092-640 \mathrm{X}(86) 90014-8$

[17] E. Acosta, X. Llovet, F. Salvat, Monte Carlo simulation of Bremsstrahlung emission by electrons, Applied Physics Letters 80 (2002) pp. 3228-3230.

DOI: $\underline{10.1063 / 1.1473684}$
[18] F. Salvat, J.M. Fernandez-Varea, J. Sempau, PENELOPE-2014: A code system for Monte Carlo simulation of electron and photon transport, Technical Report, OECD/NEA Data Bank, Issy-lesMoulineaux, 2015.

DOI: https://www.oecd-nea.org/jcms/pl 19590

[19] N. W. M. Ritchie, Spectrum simulation in DTSA-II, Microsc. Microanal. 15 (2009) pp. 454-468. DOI: $10.1017 /$ S1431927609990407

[20] Z. Czyzewski, D. O. Maccallum, A. Romig, D. C. Joy, Calculations of Mott scattering cross-section, J. Appl. Phys. 68 (1990) pp. 30663072 DOI: $10.1063 / 1.346400$

[21] A. Jablonski, F. Salvat, C. J. Powell, NIST electron elasticscattering cross-section database, National Institute of Standards and Technology, Gaithersburg, 2016. DOI: 10.6028 /NIST.NSRDS.64

[22] R. Myklebust, D. Newbury, H. Yakowitz, NBS Monte Carlo Electron Trajectory Calculation Program, in: NBS Special Publication. K. Heinrich, H. Yakowitz, D. Newbury (editors). National Bureau of Standards, Washington DC, 1976, p. 105. Online [Accessed 18 March 2021]

https://www.govinfo.gov/content/pkg/GOVPUB-C139342d46f6953c5f6a1f9a6ebc0bcc059/pdf/GOVPUB-C139342d46f6953c5f6a1f9a6ebc0bcc059.pdf

[23] D.C. Joy, S. Luo, An empirical stopping power relationship for low-energy electrons, Scanning 11 (1989) pp. 176-180. DOI: $10.1002 /$ sca.4950110404

[24] D. Bote, F. Salvat, Calculations of inner-shell ionization by electron impact with the distorted-wave and plane-wave Born approximations, Phys. Rev. A 77 (2008) art. 042701. DOI: 10.1103/PhysRevA.77.042701

[25] C. T. Chantler, K. Olsen, R. A. Dragoset, J. Chang, A. R. Kishore, S. A. Kotochigova, D. S. Zucker, NIST Standard Reference Database version 2.1, National Institute of Standards and Technology, 2005. Online [Accessed 17 March 2021] http://physics.nist.gov/ffast

[26] S. T. Perkins, D. E. Cullen, M. H. Chen, J. Rathkopf, J. Scofield, J. H. Hubbell, Tables and graphs of atomic subshell and relaxation data derived from the LLNL Evaluated Atomic Data Library (EADL), Z = 1-100, Technical Report, Lawrence Livermore National Laboratory, Berkley, 1991. DOI: $10.2172 / 10121422$

[27] N.W.M. Ritchie, Efficient simulation of secondary fluorescence via NIST DTSA-II Monte Carlo, Microscopy and Microanalysis 23 (2017) pp. 618-633.

DOI: $10.1017 / \mathrm{S} 1431927617000307$

[28] J. A. Small, The analysis of particles at low accelerating voltages $(<=10 \mathrm{kV})$ with energy dispersive $\mathrm{x}$-ray spectroscopy (EDS), J. Res. Natl. Inst. Stan. 107 (2002) pp. 555-566. DOI: 10.6028 /ires.107.047

[29] D. Moro, G. Ulian, G. Valdrè, Monte Carlo SEM-EDS micro- and nanoanalysis of ultrathin gold leaves in glass mosaic tesserae: thickness effects and measurement strategy, Measurement 129 (2018) pp. 211-217.

DOI: $\underline{10.1016 / \text { i.measurement.2018.07.025 }}$ 